\title{
Meningococcal meningitis: clinical and laboratorial characteristics, fatality rate and variables associated with in-hospital mortality
}

\author{
Meningite meningocócica: características clínicas e laboratoriais, taxa de letalidade e \\ variáveis associadas com mortalidade intra-hospitalar \\ Vanessa L. Strelow', Érique José F. Peixoto de Miranda , Karin R. Kolbe', Juliana V. Souza Framil', \\ Augusto Penalva de Oliveira², José E. Vidal ${ }^{2,4,5}$
}

\begin{abstract}
Meningococcal meningitis is a public health problem. The aim of this study was to describe the clinical characteristics of patients with meningococcal meningitis, and to identify associated factors with mortality. This was a retrospective study, between 2006 and 2011, at a referral center in São Paulo, Brazil. Logistic regression analysis was used to identify factors associated with mortality. We included 316 patients. The median age was 16 years (IQR: 7-27) and 60\% were male. The clinical triad: fever, headache and neck stiffness was observed in $89 \%$ of the patients. The cerebrospinal triad: pleocytosis, elevated protein levels and low glucose levels was present in $79 \%$ of patients. Factors associated with mortality in the multivariate model were age above 50 years, seizures, tachycardia, hypotension and neck stiffness. The classic clinical and laboratory triads of meningococcal meningitis were variable. The fatality rate was low. Age, seizures and shock signs were independently associated with mortality.
\end{abstract}

Keywords: meningitis, meningococcal; Neisseria meningitidis; epidemiology.

RESUMO

Meningite meningocócica (MM) é um problema de saúde pública. Os objetivos deste estudo foram descrever características clinicas de pacientes com MM, e identificar fatores associados à mortalidade intra-hospitalar. Trata-se de um estudo retrospectivo, entre 2006 e 2011 , em um centro de referência, São Paulo, Brasil. Análise de regressão logística multivariada foi usada para identificar fatores associados na admissão com mortalidade intra-hospitalar. Foram incluídos 316 casos. A média de idade foi 16 anos (IQR: 7-27) e 189 (60\%) eram do sexo masculino. A tríade clínica: febre, cefaléia e rigidez de nuca foi observada em 89\% dos casos. A tríade do exame de líquor: pleocitose, proteinorraquia elevada e hipoglicorraquia ocorreu em 79\% dos casos. Fatores associados à mortalidade no modelo multivariado foram: idade acima de 50 anos, convulsões, taquicardia, hipotensão e rigidez de nuca. Tríades clínicas e laboratoriais clássicas de MM foram variáveis. Na admissão, idade, convulsões, taquicardia e hipotensão associaram-se independentemente com o desfecho.

Descritores: meningite meningocócica; Neisseria meningitidis; epidemiologia.

Meningococcal meningitis (MM) is a life-threatening disease and a serious public health problem in many countries throughout Latin America ${ }^{1}$.

This disease continues to result in high fatality rates and substantial morbidity despite the sensitivity of Neiserria (N.) meningitidis to penicillin and other antibiotics ${ }^{1,2,3,4}$. Neiserria meningitidis is the main etiological agent of meningitis in non-neonate children and in young adults in Brazil, where $\mathrm{MM}$ is endemic with periodic outbreaks in several cities ${ }^{1,2,3,4,5}$.

In late 2010, Brazil was the first country in Latin America to introduce the meningococcal $\mathrm{C}$ conjugate vaccine routinely into its immunization program. The decision was based on the epidemiological status reported in the country at that time: $80 \%$ of the identified meningococcal disease patients were

${ }^{1}$ Instituto Emílio Ribas de Doenças Infecciosas, Departamento de Doenças Infecciosas, São Paulo SP, Brasil;

${ }^{2}$ Instituto Emílio Ribas de Doenças Infecciosas, Departamento de Neurologia, São Paulo SP, Brasil;

${ }^{3}$ Universidade de São Paulo, Hospital Universitário, Divisão de Clínica Médica, São Paulo SP, Brasil;

${ }^{4}$ Universidade de São Paulo, Hospital das Clinicas, Divisão de Moléstias Infecciosas, São Paulo SP, Brasil;

5Instituto de Medicina Tropical de São Paulo, Universidade de São Paulo, Laboratório de Investigação Médica (LIM) 49, São Paulo SP, Brasil.

This study was presented at the XVI Pan American Congress of Infectious Diseases. Santiago de Chile, Chile 2013. Oral presentation No. 58.

Correspondence: José E. Vidal; Instituto de Medicina Tropical de São Paulo / USP / LIM 49; Av. Dr. Enéas de Carvalho Aguiar, 470 ; $05403-000$ São Paulo SP

Brasil; E-mail: josevibe@gmail.com

Conflict of interest: There is no conflict of interest to declare.

Received 16 June 2016; Received in final form 13 July 2016; Accepted 19 July 2016. 
associated with serogroup C; incidence rates were approximately 1.6 patients/100,000 habitants, with the highest incidence rates in infants and young children; and a fatality rate as high as 20\%. ${ }^{6}$ Early trends, in 2011 and 2012, derived from population-based data demonstrated a $50 \%$ reduction in the incidence rates of meningococcal disease in children aged $<2$ years, the age group targeted for vaccination, after the introduction of the vaccine. However, no early impact was observed in other age groups. ${ }^{6}$ Thus, it is important to know clinical and laboratory information about MM in several age groups in our setting.

\section{Objectives}

The objectives of this study were to describe the clinical and laboratory characteristics of patients with MM, to estimate the fatality rate during hospitalization, and to identify associated factors with in-hospital mortality.

\section{METHODS}

We retrospectively analyzed data from the clinical records of patients with MM admitted between 2006 and 2011 at the Instituto de Infectologia Emílio Ribas (IIER), São Paulo State, Brazil. This is a 250-bed tertiary teaching hospital that principally serves a population of low and middle-low socio-economic level and it is the main referral institution for the management of patients with meningitis in São Paulo State.

Cases of MM were retrieved from the register of the epidemiology service and the cerebrospinal fluid (CSF) laboratory of our institution. The inclusion criterion was the presence of at least one laboratory result in the CSF (Gram stain, latex agglutination, counter-immune-electrophoresis, polymerase chain reaction [PCR] or culture) compatible with the presence of $N$. meningitidis.

We evaluated demographic, clinical and laboratory information using a standardized questionnaire. The fatality rate was identified. The main focus of statistical analysis was to evaluate the factors associated with in-hospital mortality. We use Mann-Whitney U and chi-square tests for comparisons. All tests were two-sided and significance was $P<0.05$. Factors associated with mortality in a univariate model with $P<0.2$ were included in the multivariate logistic regression analysis. Variables with $P \leq 0.05$ remained in the final model.

\section{Ethics}

The study was approved by the Ethical and Scientific Boards of the Instituto de Infectologia Emílio Ribas.

\section{RESULTS}

We identified 351 patients. In 35 (10\%) patients, clinical records were not available. Thus, 316 (90\%) patients were included in the study.
Pediatric and adult patients were included: $\leq 5$ years: 71 (22.2\%) patients; > 5-15 years: 88 (27.8\%) patients; >15-50 years: $133(42.2 \%)$, and > 50 years: 24 (7.6\%) patients.

The median age was 16 years (interquartile range (IQR): 7-27 years) and 186 (60\%) were male. The median time between the onset of symptoms and reaching the health system was 24 hours (IQR: 18-48 hours). The main clinical features of the patients are shown in Table 1.

The triad of fever, headache and neck stiffness was observed in $89 \%$ of the patients $(n=226)$. Only $52 \%$ of the patients presented with the triad of fever, headache and change in mental status $(\mathrm{n}=238)$.

Leukocytosis, defined as a peripheral white blood cell (WBC) count $>11,000$ cells $/ \mathrm{mm}^{3}$, was present in $89 \%$ of the patients $(n=308)$, and arterial serum lactate was elevated ( $>14 \mathrm{mg} / \mathrm{dL})$ in $48 \%$ of the patients $(\mathrm{n}=113)$. Immature forms of leukocytes were present in 187 patients $(61 \%)$. The median serum C-reactive protein was 155mg/L (IQR: 83-251), $(n=165)$.

Pleocytosis (WBC in CSF > 4 cells $/ \mathrm{mm}^{3}$ ) was observed in all but one patient (99.7\%), elevated protein levels in CSF (> $45 \mathrm{mg} / \mathrm{dL}$ ) in 311 (98.4\%) patients, and low glucose levels (defined as $<40 \mathrm{mg} / \mathrm{dL}$ ) in CSF in $312(80.3 \%$ ) patients. The triad of pleocytosis, elevated CSF protein levels and low CSF glucose levels was present in 250 (79\%) patients. Medians and interquartile range (IQR) of CSF parameters are shown in Table 2.

The frequency of the diagnostic methods used and their positive results are shown in Table 3. Cerebrospinal fluid cultures showed N. meningitidis in 70 of 218 (32\%) patients. However, susceptibility test results were available in only $12(17 \%)$ patients, all of whom showed sensitivity to penicillin, ampicillin, ceftriaxone, and chloramphenicol. Blood culture was positive only in $18(8.3 \%)$ patients.

Table 1. Signs and symptoms of patients with meningococcal meningitis.

\begin{tabular}{lc}
\hline Sign and symptom & N (\%) \\
\hline Fever, $n=307$ & $296(96 \%)$ \\
Headache, $n=245$ & $242(99 \%)$ \\
Neck stiffness, $n=288$ & $270(94 \%)$ \\
Skin lesions, $n=306$ & $222(73 \%)$ \\
Seizures, $n=280$ & $44(16 \%)$ \\
Hypotension, $n=310$ & $60(19 \%)$ \\
Tachycardia, $n=314$ & $161(51 \%)$ \\
Tachypnea, $n=289$ & $149(52 \%)$ \\
Change in mental status, $n=307$ & $170(55 \%)$ \\
Focal deficits, $n=215$ & $23(11 \%)$ \\
\hline${ }^{\star}$ Skin lesions includes petechiae, purpura, and/or echymoses.
\end{tabular}

Table 2. Cerebrospinal fluid characteristics of patients with meningococcal meningitis.

\begin{tabular}{lc}
\hline CSF parameter & Median $($ IQR $)$ \\
\hline Cell count $\left(\right.$ cells $\left./ \mathrm{mm}^{3}\right), \mathrm{n}=313$ & $5,552(2,228-10,485)$ \\
Protein $(\mathrm{mg} / \mathrm{dL}), \mathrm{n}=311$ & $300(163-514)$ \\
Glucose $(\mathrm{mg} / \mathrm{dL}), \mathrm{n}=310$ & $10(5-34)$ \\
\hline
\end{tabular}


Among patients with available data $(\mathrm{n}=255), 189(74 \%)$ received at least one dose of antibiotics prior to performing the CSF culture. Among the patients with negative CSF culture ( $\mathrm{n}=148), 136(92 \%)$ received antibiotics prior to the exam, whilst among those with positive CSF culture $(\mathrm{n}=70)$ only $18(26 \%)$ had already received the medication before of the procedure $(\mathrm{p}<0.05)$.

The N. meningitidis serotype was identified in 206 patients. The most frequent was serotype $\mathrm{C}(84.5 \%, \mathrm{n}=184)$. The other serotypes were: $\mathrm{B}, \mathrm{n}=22$ (10.7\%), W135, $\mathrm{n}=8$ (3.9\%); $\mathrm{A}, \mathrm{n}=1$ (0.5\%); and W135 and Y (simultaneously), $\mathrm{n}=1(0.5 \%)$.

A brain computerized tomography (CT) scan was performed in $162(51 \%)$ patients at the moment of, or during, hospitalization. In 128 patients, it was possible to establish the order between brain CT scan and results of CSF culture. In 28 (21.9\%) patients, the brain CT scan was performed before the CSF culture. Thus, in most patients (78.1\%), the clinical decision was to perform a CSF culture without a prior brain CT scan.

In 189 patients, it was possible to establish the order between the moment of antibiotic administration and results of the lumbar puncture. In 140 (74.1\%) patients, the antibiotic was administered before the lumbar puncture.

Ceftriaxone was the first antibiotic administered in 274 (87\%) patients. Of these, ampicillin or penicillin was the antibiotic of choice administered in 195 (71\%) patients when the diagnosis of meningococcal meningitis was confirmed.

The median time of administration of antibiotics was seven days (IQR: 5-9 days). At least one dose of corticosteroids was given to $94 \%$ of the patients. Of the 316 patients, $67 \%$ were admitted to the intensive care unit.

Two $(0.6 \%)$ patients underwent neurosurgery.

The fatality rate was $5.4 \%(17 / 316)$. The results by age groups were: $\leq 5$ years: $2(2.8 \%)$ patients; $>5-15$ years: $1(1.2 \%)$ patient; >15-50 years: 9 (6.6\%) patients, and > 50 years: $5(22.7 \%)$ patients.

The comparison between survivors and nonsurvivors resulted in a statistically significant difference between the variables and is shown in Table 4.

Factors associated with mortality in the multivariate model were: age $\geq 50$ years (OR 21.65, 95\%CI: $2.46-190.22, \mathrm{p}=0.006$ ), seizures (OR 4.64, 95\%CI 1.06-20.28, $\mathrm{p}=0.042$ ), tachycardia (OR 23.37, 95\%CI, 2.46-221.78, $\mathrm{p}=0.006$ ), hypotension (OR 20.28, 95\%CI, 3.00-136.87, $\mathrm{p}=0.002$ ) and neck stiffness (OR 0.16, $95 \%$ CI, 0.005-0.47, p = 0.001) (Table 5). Serogroup C vs. other was not significant in univariate analysis $(\mathrm{p}=0.618)$.

\section{DISCUSSION}

In this study, typical clinical and laboratory features of MM were common but classical triads were variable; the fatality rate was low; and age above 50 years, seizures, tachycardia and hypotension were directly associated with mortality, and neck stiffness was inversely associated with this outcome.
In this study, the median age was 16 years and approximately $20 \%$ of patients were $\leq 5$ years old. However, meningococcal meningitis is classically more common in children. For example, approximately $40 \%$ of the patients with MM in the state of São Paulo, Brazil, were $\leq 4$ years old. ${ }^{7}$ In Brazil, between 2000 and 2010, the majority of patients occurred among two- to four-year-old children, before the introduction of meningococcal vaccines into the routine vaccination schedule ${ }^{8}$. This difference is due to the predominant profile of adult patients admitted to our hospital.

Table 3. Frequency of positivity of several techniques in the diagnosis of meningococcal meningitis.

\begin{tabular}{lc}
\hline Diagnostic method & $\begin{array}{c}\text { Frequency of } \\
\text { positivity, } \mathrm{n}(\%)\end{array}$ \\
\hline Gram stain, $\mathrm{n}=306$ & $274(90 \%)$ \\
Latex agglutination, $\mathrm{n}=247$ & $191(77 \%)$ \\
Counter-immune-electrophoresis, $\mathrm{n}=95$ & $49(52 \%)$ \\
Polymerase chain reaction, $\mathrm{n}=111$ & $101(91 \%)$ \\
Culture, $\mathrm{n}=218$ & $70(32 \%)$ \\
\hline
\end{tabular}

Table 4. Comparison of clinical, laboratory and radiological variables between survivors and nonsurvivors.

\begin{tabular}{lccc}
\hline Variable & Survivor & Nonsurvivor & p-value \\
\hline $\begin{array}{l}\text { Age (in months), } \\
\text { median, IQR }\end{array}$ & $180(72-312)$ & $372(228-381)$ & $0.002^{*}$ \\
Meningoencephalitis & $169(56.5)$ & $15(88.2)$ & $0.020^{*}$ \\
Septic shock & $32(10.7)$ & $14(82.4)$ & $<0.0001^{*}$ \\
Seizures & $38(14.3)$ & $6(42.9)$ & $0.012^{*}$ \\
Hypotension & $47(16.0)$ & $13(76.5)$ & $<0.0001^{*}$ \\
Neck stiffness & $265(94.9)$ & $5(55.5)$ & $<0.0001^{*}$ \\
Altered mental status & $155(53.3)$ & $15(93.8)$ & $0.006^{*}$ \\
Leukocytosis & $261(89.7)$ & $12(70.6)$ & $0.043^{*}$ \\
Pleocytosis & $298(100)$ & $14(93.3)$ & $0.034^{*}$ \\
Corticosteroids & $277(92.6)$ & $14(87.5)$ & $0.014^{*}$ \\
Length of stay, median, & $9(7-13)$ & $3(1.5-5)$ & $<0.0001^{*}$ \\
IQR & $194(64.9)$ & $16(94.1)$ & $0.026^{*}$ \\
\hline Intensive care unit & IQR: interquartile range. * $p$-values statistically significant. &
\end{tabular}

Table 5. Multivariate model showing variables associated with intra-hospital mortality of patients with meningococcal meningitis.

\begin{tabular}{|c|c|c|c|}
\hline Variable & OR & $95 \% \mathrm{Cl}$ & $p$-value \\
\hline Age $\geq 50$ years & 21.65 & $2.46-190.22$ & $0.006^{*}$ \\
\hline $\begin{array}{l}\text { Time between onset of } \\
\text { symptoms and first medical } \\
\text { consultation } \geq 12 \text { hours }\end{array}$ & 2.01 & $0.27-4.46$ & 0.477 \\
\hline Neck stiffness & 0.16 & $0.005-0.47$ & $0.001 *$ \\
\hline Seizures & 4.64 & $1.06-20.28$ & $0.042^{\star}$ \\
\hline Tachycardia & 23.37 & $2.46-221.78$ & $0.006^{*}$ \\
\hline Hypotension & 20.28 & $3.00-136.87$ & $0.002^{*}$ \\
\hline Focal deficit & 0.61 & $0.16-2.28$ & 0.459 \\
\hline Glasgow Coma Scale $<15$ & 1.06 & $0.26-4.46$ & 0.930 \\
\hline Meningoencephalitis & 16.81 & $0.73-389.90$ & 0.079 \\
\hline Leukocyte $>11,000$ cells $/ \mathrm{mm}^{3}$ & 2.17 & $0.27-17.50$ & 0.467 \\
\hline CSF: $<500$ cells $/ \mathrm{mm}^{3}$ & 3.11 & $0.22-43.60$ & 0.400 \\
\hline
\end{tabular}


The majority of our patients had a classic clinical presentation of MM. Fever, headache, and neck stiffness were present at rates of $96 \%, 99 \%$, and $94 \%$ respectively, in our patients. These figures were $62 \%, 91 \%$, and $81 \%$ respectively, in another study 9 . In a Brazilian series, these features occurred in $92 \%-98 \%$, $82 \%-86 \%$ and $41 \%-90 \%$ in the adult population ${ }^{10,11}$.

When we combined these three clinical characteristics, we observed that $89 \%$ of our patients presented with this triad. In addition, petechial exanthem was present in $73 \%$ of our patients, while only $41 \%$ to $56 \%$ of patients, excluding individuals with isolated meningococcemia, showed this feature in the other studies ${ }^{9,10,11}$.

This classic presentation of MM probably facilitated the diagnostic suspicion in most patients. At least one episode of seizure was described in $16 \%$ of our sample. In contrast, two prior studies reported $1 \%$ and $5 \%$ of seizures ${ }^{9,12}$. The Brazilian series found $14 \%$ to $16 \%^{10,11}$. One of these two Brazilian studies found a predominance of seizure among subjects with ages $>49$ years ${ }^{11}$.

On the other hand, a focal deficit was present in $11 \%$ of our patients while this alteration was reported in $5 \%$ to $7 \%$ of the Brazilian series ${ }^{10,11}$ and $22 \%$ to $33 \%$ in other studies ${ }^{2,12}$.

A change in mental status was present in $55 \%$ of our patients, similar to the $50 \%$ and $57 \%$ described in another studies $^{9,11}$. A total of $52 \%$ of our patients presented with the triad of fever, headache and change in mental status, while these three characteristics were concomitantly found in only $27 \%$ of the patients in another study ${ }^{9}$. The differences in these results may be due to sample characteristics as well as to the methodologies of the studies.

The CSF parameters in our study were also typical of acute bacterial meningitis, and $79 \%$ of the patients had the triad of pleocytosis, elevated CSF protein and low CSF glucose. However, approximately $20 \%$ of patients did not present with concomitant alterations in these three parameters, which may complicate the diagnosis in this subset of patients. Our CSF data are similar with another study ${ }^{10}$.

The positivity of the Gram staining method was very high in our sample (90\%), reinforcing the value of this inexpensive, easy, and widely-available method. Although the sensitivity for the detection of MM is approximately $75 \%$ in the literature, the positivity of this method is highly variable (30-89\%), principally due to fact that accurate readings depend on the experience of the observer $2,3,4,9,12,13,14$. The positivity of CSF culture was only $32 \%$ in the present study. However, the sensitivity of CSF cultures before the start of treatment is usually high $(>80-90)^{14}$. Seventy-four percent of our patients received antibiotics prior to the lumbar puncture, and this is probably the main cause of failure to identify the causative organism ${ }^{2,15}$. Cerebrospinal fluid cultures become sterile in $90 \%$ to $100 \%$ of patients within 24 to 36 hours of administration of appropriate antimicrobial therapy ${ }^{4}$. Most recently, it has been suggested that CSF sterilization may occur more rapidly than previously reported, with complete sterilization of CSF containing meningococci within two hours of the first dose $e^{4}$.
Because CSF Gram stain and culture do not always identify $N$. meningitidis, other methods are necessary, though they are not routinely available in most resource-limited settings. In this study, $77 \%$ of patients were diagnosed with latex agglutination. However, reported sensitivity to this method is highly variable $(22-93 \%)^{3}$. In addition, lack of sensitivity in detecting bacterial antigens has been reported in the CSF of patients with culture-negative meningitis ${ }^{16}$ and a strong decline in sensitivity (from $60 \%$ to $9 \%$ ) has been reported after treatment ${ }^{2}$. The diagnostic method that positively identified most patients in this study was PCR (91\% positivity). The sensitivity and specificity of PCR for the diagnosis of meningococcal meningitis using a sample of CSF are between $89-100 \%$ and 95-100\%, respectively ${ }^{2,13,14,15,16}$. Polymerase chain reaction is increasingly used for the diagnosis of MM, including serogrouping and multilocus sequence typing ${ }^{17}$. The PCR is especially useful when Gram stain, culture, and/or latex agglutination are negative ${ }^{17}$. This method has improved sensitivity in developed countries and as well as in Brazil ${ }^{15}$. Its performance is not altered by previous antibiotic use and the results are typically obtained much faster than those of culture ${ }^{15,17}$.

Similar to our results, in the last decade, the proportion of meningococcal disease associated with group $\mathrm{C}$ increased in Brazil, according to a nationwide database, while the proportion of group B disease progressively declined ${ }^{8}$, contrasting with some Brazilian series in the same period ${ }^{11,18,19}$. Contrary to our results, in one of these series, serogroup B was independently associated with an increased fatality rate ${ }^{18}$.

In accordance with current recommendations for empirical treatment of acute bacterial meningitis ${ }^{3}$, most patients of this study received ceftriaxone. Given the description of $N$. meningitidis strains with intermediate resistance to penicillin, and the extreme severity of meningococcal disease, this initial approach seems to be reasonable ${ }^{20}$. Interestingly in this study, most patients with initial ceftriaxone administration were switched to penicillin or ampicillin after the diagnosis of meningococcal disease and not necessarily after the availability of a susceptibility test (only $17 \%$ of samples with cultures showing $N$. meningitidis had this test). Formal recommendations consist of adjusting the treatment when a susceptibility test permits ${ }^{5}$. However, ceftriaxone was changed in a subgroup of patients on an empirical basis. There are uncommon reports of penicillin resistance around the world; however, a description of strains with intermediate susceptibility to penicillin is a concern ${ }^{19}$. The SIREVA II network evaluated the resistance profile of 506 Brazilian strains of $N$. meningitidis from patients with invasive disease. Of these, $87 \%$ showed susceptibility to penicillin, $13 \%$ had intermediate susceptibility, and no sample was classified as resistant ${ }^{5}$. Although the clinical significance of intermediate susceptibility remains controversial, it seemed to be more prudent to change ceftriaxone to penicillin or ampicillin only when susceptibility to penicillin has been demonstrated. In 
SIREVA II, all tested strains were susceptible to chloramphenicol, confirming its value as an alternative for patients who are allergic to beta-lactams ${ }^{6}$. Another Brazilian study demonstrated the decreased susceptibility to penicillin and ampicillin, detected in $13 \%$ and $12.9 \%$ respectively; but all isolates were susceptible to chloramphenicol, ceftriaxone, and ciprofloxacin, in the same period as this study ${ }^{21}$.

Although the design of the present study precludes any recommendation about the use corticosteroids in MM, a recent study provides Class III evidence that adjuvant dexamethasone in adults with this disease reduces the likelihood of immune-mediated arthritis and it was not harmful ${ }^{9}$. Nowadays, it seems reasonable not to discontinue empiric treatment with dexamethasone in patients with suspected or proven meningococcal meningitis ${ }^{9,22}$.

The fatality rate in our study was $5 \%$. Fatality rates reported in developed countries vary between $3 \%$ and $13 \%$. $^{3,9,12,23,24}$ Similarly, in Brazil these vary from $2 \%$ to $14 \%^{10,11,18,19}$. However, outcomes of meningococcal disease vary depending on the clinical presentation. For example, in São Paulo, the overall fatality rate of meningococcal disease is approximately $20 \%{ }^{7}$. However, the figures for meningococcemia, meningitis, and meningococcemia plus meningitis are $36 \%$ to $43.5 \%, 2 \%$ to $10 \%$, and $9 \%$ to $22 \%$, respectively ${ }^{11,18,25}$.

The results of the present study indicate that low fatality rates are possible, at least in referral centers from low and middle-income countries. Some important interventions in most patients could explain these results: the early administration of appropriate antibiotics, lumbar puncture without prior CT, and the availability of an intensive care unit in our institution.

In this study, factors directly associated with mortality in the multivariate model were age above 50 years, seizures, tachycardia, and hypotension. The only factor inversely associated with mortality was neck stiffness. Several studies demonstrated the association between older patients and unfavorable outcome $e^{3,18,22,23,24,25,26}$. We believe that the higher mortality in this group is explained, at least in part, by the concomitant presence of other conditions and to a delay in the diagnosis of MM, since older patients require a particular differential diagnosis of several acute neurological syndromes. Shock signs (i.e. hypotension, tachycardia) are classically associated with higher mortality in patients with acute bacterial meningitis ${ }^{3,12,18,27,28}$. The importance of seizures in the outcome of acute bacterial meningitis has also been noted in other studies ${ }^{10,28,29,30}$. Thus, along with early diagnosis and initiation of antibiotics, transfer to an intensive care unit and aggressive management of shock are critical to improve the survival of patients with MM. Finally, we found that neck stiffness was inversely associated with mortality in our study because this is a classic sign of meningitis and its presence supports the clinical suspicion.

In conclusion, in this study typical clinical and laboratory presentations were common but classic triads were variable. The fatality rate was low. Age above 50 years, seizures, tachycardia and hypotension were directly associated with mortality and neck stiffness was inversely associated with this outcome.

\section{Acknowledgements}

We thank Ana Paula Lemos (Instituto Adolfo Lutz, São Paulo State, Brazil) and Camile Moraes (Departamento de Vigilância Epidemiológica, Secretaria de Vigilância em Saúde, Ministério da Saúde do Brasil) for the epidemiological data of meningococcal disease in São Paulo and Brazil. Jim Hesson of AcademicEnglishSolutions.com revised the English language.

\section{References}

1. Sáfadi MAP, Cintra OAL. Epidemiology of meningococcal

disease in Latin America: current situation and

opportunities for prevention. Neurol Res. 2010;32(3):263-71.

doi:10.1179/016164110X12644252260754

2. Brouwer MC, Tunkel AR, Beek D. Epidemiology, diagnosis, and antimicrobial treatment of acute bacterial meningitis. Clin Microbiol Rev. 2010;23(3):467-92. doi:10.1128/CMR.00070-09

3. Heckenberg SGB, Gans J, Brouwer MC, Weisfelt M, Piet JR, Spanjaard $L$ et al. Clinical features, outcome, and meningococcal genotype in 258 adults with meningococcal meningitis: a prospective cohort study. Medicine (Baltimore). 2008;87(4):185-92. doi:10.1097/ MD.0b013e318180a6b4

4. Tunkel AR, Beek D, Scheld WM. Acute meningitis. In: Mandell, Douglas and Bennett's Principles and practice of infectious diseases. 7th ed. Philadelphia: Churchill Livingstone Elsevier; 2010. p. 1189-229.

5. Organización Panamericana de la Salud. Informe Regional de SIREVA II, 2010: datos por país y por grupos de edad sobre las características de los aislamiento de Streptococccus pneumoniae, Haemophilus influenzae y Neisseria meningitidis em procesos invasores. Washington, DC: Organización Panamericana de la Salud; 2011.

6. Sáfadi MA, Berezin EN, Arlant LH. Meningococcal disease: epidemiology and early effects of immunization programs. J Pediatric Infect Dis Soc. 2014;3(2):91-3. doi:10.1093/jpids/piu027

7. Secretaria de Estado da Saúde (SP), Centro de Vigilância Epidemiológica. Dados estatísticos de doença meningocócica, São Paulo; 2012 [acess 2012 Aug 13]. Available from: http://www.cve.saude.sp.gov.br/htm/resp/meni_dados.html

8. Azevedo LC, Toscano CM, Bierrenbach AL. Bacterial meningitis in Brazil: baseline epidemiologic assessment of the decade prior to the introduction of pneumococcal and meningococcal vaccines. PLoS One. 2013;8(6):e64524. doi:10.1371/journal.pone.0064524

9. Heckenberg SGB, Brouwer MC, Ende A, Beek D. Adjunctive dexamethasone in adults with meningococcal meningitis. Neurology. 2012;79(15):1563-69. doi:10.1212/WNL.0b013e31826e2684

10. Cordeiro SM, Neves AB, Ribeiro CT, Petersen ML, Gouveia EL, Ribeiro GS et al. Hospital-based surveillance of meningococcal meningitis in Salvador, Brazil. Trans R Soc Trop Med Hyg. 2007;101(11):1147-53. doi:10.1016/j.trstmh.2007.06.012 
11. Barroso DE, Carvalho DM, Casagrande ST, Rebelo MC, Soares $\mathrm{V}$, Zahner $\mathrm{V}$ et al. Microbiological epidemiological history of meningococcal disease in Rio de Janeiro, Brazil. Braz J Infect Dis. 2010;14(3):242-51. doi:10.1016/S1413-8670(10)70051-9

12. Beek D, Gans J, Spanjaard L, Weisfelt M, Reitsma JB, Vermeulen M. Clinical features and prognostic factors in adults with bacterial meningitis. N Engl J Med. 2004;351(18):1849-59. doi:10.1056/NEJMoa040845

13. Gans J, Beek D. Dexamethasone in adult with bacterial meningitis. N Engl J Med. 2002;347(20):1549-56. doi:10.1056/NEJMoa021334

14. Brouwer M, Thwaites GE, Tunkel AR, Beek D. Dilemmas in the diagnosis of acute community-acquired bacterial meningitis. Lancet. 2012;380(9854):1684-92. doi:10.1016/S0140-6736(12)61185-4

15. Sacchi CT, Fukasawa LO, Gonçalves MG, Salgado MM, Shutt KA, Carvalhanas TR et al. Incorporation of real-time PCR into routine public health surveillance of culture negative bacterial meningitis in São Paulo, Brazil. PLos One. 2011;6(6):e20675. doi:10.1371/journal.pone.0020675

16. Tarafdar K, Rao S, Recco RA, Zaman MM. Lack of sensitivity of the latex agglutination test to detect bacterial antigen in the cerebrospinal fluid of patients with culture-negative meningitis. Clin Infect Dis. 2001;33(3):406-8. doi:10.1086/321885

17. Stephens DS, Greenwood B, Brandtzaeg P. Epidemic meningitis, meningococcaemia, and Neisseria meningitidis. Lancet. 2007;369(9580):2196-210. doi:10.1016/S0140-6736(07)61016-2

18. Donalisio MR, Kemp B, Rocha MM, Ramalheira RM. [Case fatality rate for meningococcal disease: study in the region of Campinas, SP, Brazil 1993 to 1998]. Rev Saúde Pública. 2000;34(6):589-95. Portuguese. doi:10.1590/S0034-89102000000600005

19. Santos ML, Ruffino-Netto A. [Meningococcal disease: epidemiological profile in the Municipality of Manaus, Amazonas, Brazil, 1998/2002]. Cad Saúde Pública. 2005;21(3):823-9. Portuguese. doi:10.1590/S0102-311X2005000300016

20. Vásquez JA. Resistance testing of meningococci: the recommendations of the European Monitoring Group on Meningococci. FEMS Microbiol Rev. 2007;31(1):97-100. doi:10.1111/j.1574-6976.2006.00050.x
21. Gorla MC, Paiva MV, Salgueiro VC, Lemos AP, Brandão AP, Vázquez JA et al. Antimicrobial susceptibility of Neisseria meningitidis strains isolated from meningitis cases in Brazil from 2006 to 2008. Enferm Infecc Microbiol Clin. 2011;29(2):85-9. doi:10.1016/j.eimc.2010.07.016

22. Brust JC. Meningococcal meningitis, dexamethasone, and Class III evidence. Neurology. 2012;79(15):1528-9. doi:10.1212/WNL.0b013e31826e7398

23. Thigpen MC, Whitney CG, Messonnier NE, Zell ER, Lynfield R, Hadler $\mathrm{JL}$ et al. Bacterial meningitis in the United States, 1998-2007. N Engl J Med. 2011;364(21):2016-25. doi:10.1056/NEJMoa1005384

24. Schut ES, Gans J, Beek D. Community-acquired bacterial meningitis in adults. Pract Neurol. 2008;8(1):8-23. doi:10.1136/jnnp.2007.139725

25. Ministério da Saúde (BR). Sistema de Informação de Agravos de Notificação - Sinan Net. Brasília, DF; 2013 [acess 2013 Mar 20]. Available from: http://dtr2004.saude.gov.br/sinanweb/index.php

26. Gil-Prieto R, García-García L, Álvaro-Meca A, González-Escalada A, Viguera Ester P, De Miguel AG. The burden of hospitalizations for meningococcal infection in Spain (1997-2008). Vaccine. 2011;29(34):5765-70. doi:10.1016/j.vaccine.2011.05.089

27. Chang WN, Lu CH, Huang CR, Tsai NW, Chuang YC, Chang CC et al. Changing epidemiology of adult bacterial meningitis in southern Taiwan: a hospital-based study. Infection. 2008;36(1):15-22. doi:10.1007/s15010-007-7009-8

28. Cabellos C, Verdaguer R, Olmo M, Fernández-Sabé N, Cisnal M, Ariza J. et al. Community-acquired bacterial meningitis in elderly patients: experience over 30 years. Medicine (Baltimore). 2009;88(2):115-9. doi:10.1097/MD.0b013e31819d50ef

29. Lai WA, Chen SF, Tsai NW, Chang CC, Chang WN, Lu CH et al. Clinical characteristics and prognosis of acute bacterial meningitis in elderly patients over 65: a hospital-based study. BMC Geriatr. 2011;11(1):91. doi:10.1186/1471-2318-11-91

30. Zoons E, Weisfelt M, de Gans J, Spanjaard L, Koelman $\mathrm{JH}$, Reitsma JB et al. Seizures in adults with bacterial meningitis. Neurology. 2008;70(22 Pt 2):2109-15. doi:10.1212/01.wnl.0000288178.91614.5d 